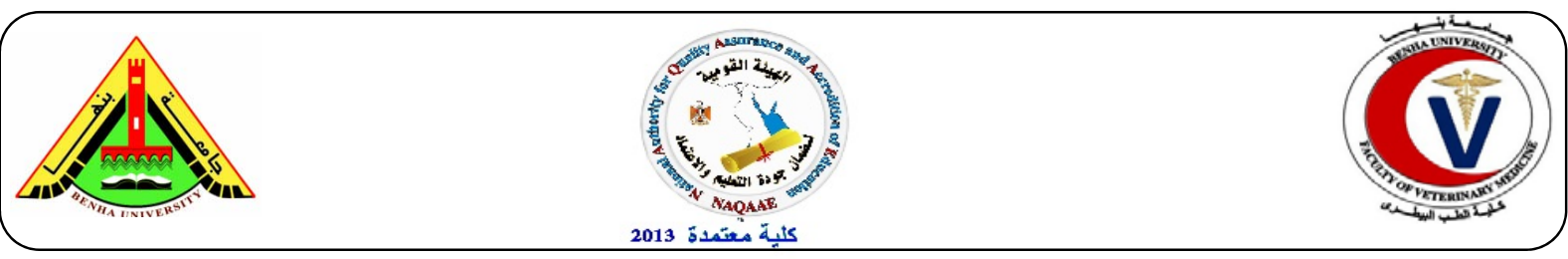

\title{
Pathological study on urea utilization by poultry
}

\author{
Mahmoud S. Gaballah', Abd- Elbasat I. El-Mashad', Dalia F. Khater ${ }^{2}$ and Rasha M. Zayed ${ }^{2}$ \\ ${ }^{1}$ Pathology department, faculty of veterinary medicine, Benha University. \\ ${ }^{2}$ Animal health research institute, Tanta lab.
}

\section{A B S T R A C T}

\begin{abstract}
The present work aimed to investigate the histopathological aspects, growth performance, urea residue in muscle and liver of broiler birds and chemical composition of the breast muscles in birds fed graded levels of urea -treated ration. 80, day old chicks were reared for 6 weeks. After one week of age, chicks were randomly divided into 4 equal groups fed on $1.25 \%, 2.5 \%, 5 \%$ and $0 \%$ urea in their ration. Five birds from each group were sacrificed at the day 7, 14, 28 and 35 from adding urea. The most clinical signs were respiratory symptoms, watery diarrhea and staggering gait. Body weight and feed consumption were increased in group I \& II, while the group III showed mild decrease. Urea residue in muscle and liver increased significantly in group III when comparing with other groups. The chemical composition of the muscle showed that the moisture content in group III was high than group IV. There was non-significant increase in the crude protein level in group II. There was significant increase in ash percent in group II. The fat content in the muscle of all urea treated groups was significant decrease than IV group. Grossly, kidneys and the liver were severe enlarged with pale anemic and mottled coloration. Lungs and the muscles were severe congested and dark brownish color with petechial and linear hemorrhage in muscle. The brain showed mild hyperemia. Histopathological examination in the kidneys showed degenerative changes in the epithelial cell lining of the renal tubules. The glomeruli showed shrinkages of their glomerular tuft and hyalinization of the Bowman's capsules. Liver showed focal areas of necrosis in the hepatic parenchyma. There was severe thickening of the hepatic capsule. The bile duct showed hyperplasia of their epithelial cell lining with the presence of desquamated epithelia in the ductile lumen with newly formed bile ductile. Most of hepatic and pulmonary blood vessels showed thrombosis. Lungs and muscle and brain showed congestion of the blood vessels. The bronchioles showed catarrhal bronchopneumonia. There was osseous metaplasia among the pulmonary tissue. The neuron was suffering from Tygrloysis with presence of satellotosis and neurophagia. The intestine showed degenerative changes. Myomalecia of some muscle cell and suffering from mild degree of hyaline degeneration. It is recommended that lower inclusion levels of urea diets $(1.25 \%)$ rather than the $2.5 \%$ and $5 \%$ used in this study be employed for a short period of time.
\end{abstract}

Keyword: urea -residue -histopathological -broiler birds.

(http://www.bvmj.bu.edu.eg)

(BVMJ-33(2): 65-74, DECEMBER, 2017)

\section{INTRODUCTION}

Urea is a commonly used as a fertilizer and it has replaced other major nitrogen fertilizers because it is non-explosive and comparatively safe to handle. Urea is being considered for feeding ruminant animals as a non-protein nitrogenous (NPN) substance to supply a part of protein needs for growth (Maynard et al., 1985); but little is known about its effects on different species of poultry particularly with regard to its influence on production characteristics. On the other hand, Urea is occasionally present in higher levels in the poultry feed owing to adulteration of poultry feed formulation. Urea has been used as a cheap protein substitute in the poultry feed (Pervaz et al., 1993). However, toxicity can occur when chicks are kept on urea treated feed (Jabbar, 1994; Pervaz, 1994; Abdou et al., 2006). Recently, commercial pet food was adulterated with melamine (Brown et al.,
2007). Melamine is an organic base commercially synthesized from urea with an intermediate step producing cyanic acid. Incidences of nephrolithiasis in children from the Chinese adulteration incident have also been published (Liu et al., 2010). Recently, toxicological data and risk assessments for melamine in livestock, laboratory animals, pets, fish and shrimp have been reviewed (WHO. 2008; Sharma \& Paradakar 2010; Dorne et al., 2013). In non- ruminants, some researchers have suggested that urea is unable to be utilized and that it has no nutritional value for poultry (Kobayashi et al., 1981). Others suggest that urea may replace some non- essential amino acids in diet of non-ruminants (Sucio et al., 1990b). However, significant increase in mass gain has been observed when low levels of urea were used in broiler chicks (Pervaz et al., 1996). 
This work aimed to study the histopathological aspects, growth performance, chemical composition of the muscles and urea residue in liver and breast meat of broiler birds fed graded levels of urea-treated ration.

\section{MATERIALS AND METHODS}

Eighty day old chicks were used. After one weeks of age, chicks were randomly divided into 4 equal groups (I, II, III and IV), 20 birds in each. Urea was added to the feed for successive 35 days at the levels of $1.25 \%$ (group I), $2.5 \%$ (group II) and $5.0 \%$ (group III) while the birds of group IV served as control. The performance parameters as body weight gain; feed consumption and feed conversion rate were measured weekly. Five birds from each group at the day 7, 14, 28 and 35 from adding urea were sacrificed. At the end of the experiment at 42-day old age samples from the breast muscle and liver from each group birds were obtained for urea residue analysis according to (AOAC 1990) and also for chemical composition analysis to determine moisture content (Daszkiewicz et al., 2012), crude protein percentage and, Lipid percentage (Damron, 2006) and Ash content (AOAC, 2000). For histopathological examination, specimens were obtained from liver, kidney, lung, muscle, intestine and brain. Then were prepared and stained with hematoxylin and eosin according to Bancroft et al. (1996).

\section{RESULTS}

The predominant clinical signs were respiratory symptoms (sneezing, wheezing, coughing, and runny nose and eyes), watery diarrhea and staggering gait. Body weight and feed consumption were increased in group I and II, while the results of group III showed mild decrease. Moreover, there was no difference in the FCR between the urea treated groups and control at the end of the experiment (Table, 1).

\subsection{Detection of urea concentration in the muscle and liver:}

The urea residue in the muscle and liver of the group which was taken ration containing 5\% urea was showed significant value when comparing with the control (Table, 2).

\subsection{Results of the chemical composition of the muscle:}

The chemical composition of the muscle of the experimental chicks showed that the moisture content in the muscle of 5\% urea treated group was higher than the control group. There was nonsignificant increase in the crude protein level $(P$ value $<0.05$ ) in birds fed $2.5 \%$ urea but there was significant increase in ash percent $(P$ value $<0.05)$ in the same group. The fat content in the muscle of all urea treated groups was significant decrease $(P$ value $<0.05)$ than the control group Table, (3).

\subsection{Macroscopical findings:}

Grossly, the kidneys were enlarged and pale in color with dark red areas of hemorrhages on the surface (Fig. 1). Occasionally, the ureters of chicks fed 5\%urea were distended with urates. The livers were swollen, congested or mottled with rounded borders and distended gall bladder (Fig. 2). Occasionally, the liver was yellow in color and exhibited minute necrotic foci on cut section. The lungs were congested and edematous or dark brown in color. The brains were slightly hyperemic and the breast muscles were congested with occasional petechial or linear hemorrhage on the surface. These lesions were more pronounced in group II and III.

\subsection{Histopathological examination:}

The kidneys in group I showed mild degenerative changes in the form of vacuolation in the cytoplasm of their lining epithelial cell, perivascular hemorrhage and mononuclear cell infiltration were observed in group II. Focal areas of necrosis infiltrated with leucocytes. In group III, the glomeruli showed shrinkages of their glomerular tuft, thickening and hyalinization of the Bowman's capsules as well as degenerative changes. Moreover, the renal tubules showing severe degree of desquamation of their epithelial cell lining with the presence of hyaline casts in their lumen.

Liver in group I showed focal areas of necrosis in the hepatic parenchyma infiltrated with mononuclear leukocytes. Liver in group II and III showed vacuolar and hydropic degeneration or even fatty changes in the cytoplasm of hepatocyte and severe thickening of the hepatic capsule. Massive areas of hemorrhage among the hepatic parenchyma. The bile duct showed hyperplasia of their epithelial cell lining with the presence of desquamated epithelia in the ductile lumen with newly formed bile ductile and mild portal fibrosis. The hepatic blood vessels and hepatic sinusoids showed severe congestion and dilatation with occasional thrombosis.

Lungs of group I showed mild congestion of the pulmonary blood vessels and inter alveolar blood capillaries. The bronchioles showed mild degree of 
catarrhal bronchitis but after 5 weeks from urea administration clear catarrhal bronchopneumonia was found. Perivascular hemorrhage of the pulmonary blood vessels and the endothelial cell lining of the pulmonary blood vessels were suffering from degenerative changes. Lungs of group II and III showed perivascular edema and hemorrhage infilterated with leukocytes. The bronchioles showed hyperplasia with presence of eosinophilic exudate in their lumen. Severe congestion and dilatation of the pulmonary blood vessels. The pulmonary blood vessels showed the presence of thrombosis in their laminae. There was osseous metaplasia among the pulmonary tissue.

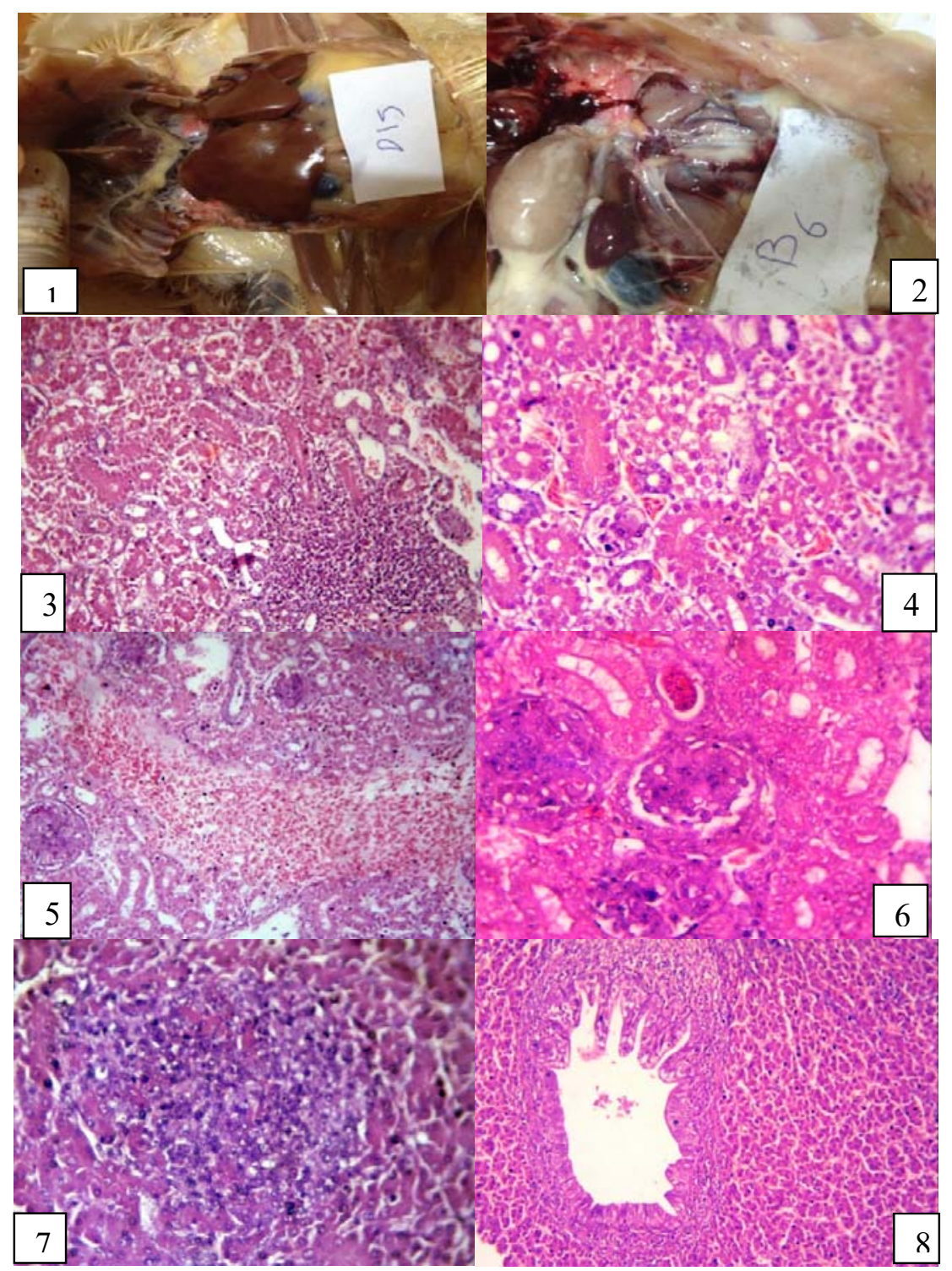

(Fig. 1) Grossly kidneys of chicken after 2 weeks from urea administration by concentration of $2.5 \%$ showing enlargement, pale in color and exhibited dark red areas of hemorrhage. (Fig. 2) chicken after 4 weeks from urea administration by concentration of 5\% showing swelling, mottling of liver with rounded borders and distended gall bladder. (Fig. 3) kidneys of chicken after 4 weeks from urea administration by concentration of $1.25 \%$ showing focal leukocytic aggregation in the renal medulla. H\&E x 100.(Fig. 4) Kidneys of chicken after 2 weeks from urea administration by concentration of $2.5 \%$ showing severe vacuolation of tubular epithelium and congestion of the intertubular blood capillaries. H\&E x 200. (Fig. 5) Kidneys of chicken after 5 weeks from urea administration by concentrarion of $2.5 \%$ showing focal area of hemorrahage scattered in the renal cortex. (H\&E x 100). (Fig. 6) Kidneys of chicken after one week from administration of urea by concentration of 5\% showing thickening, hyperplasia and hypertrophy of parietal epithelium of the Bowman's 
capsule. Note also enlargement of other glomerular tuft with increased mesangial cellularity. (H\&E x200). (Fig. 7) Liver of chicken after 2 weeks from urea administration by concentration of $1.25 \%$ showing focal area of necrosis in the hepatic parenchyma represented by fine granular eosinophilic and basophilic substances infiltrated with leukocyte. (H\&E x 400). (Fig. 8) Liver of chicken after 4 weeks from urea administration by concentration of $2.5 \%$ showing hyperplasia of the epithelial cell lining the bile duct with periductal leukocytic infiltration and fibrosis. H\&E x 200

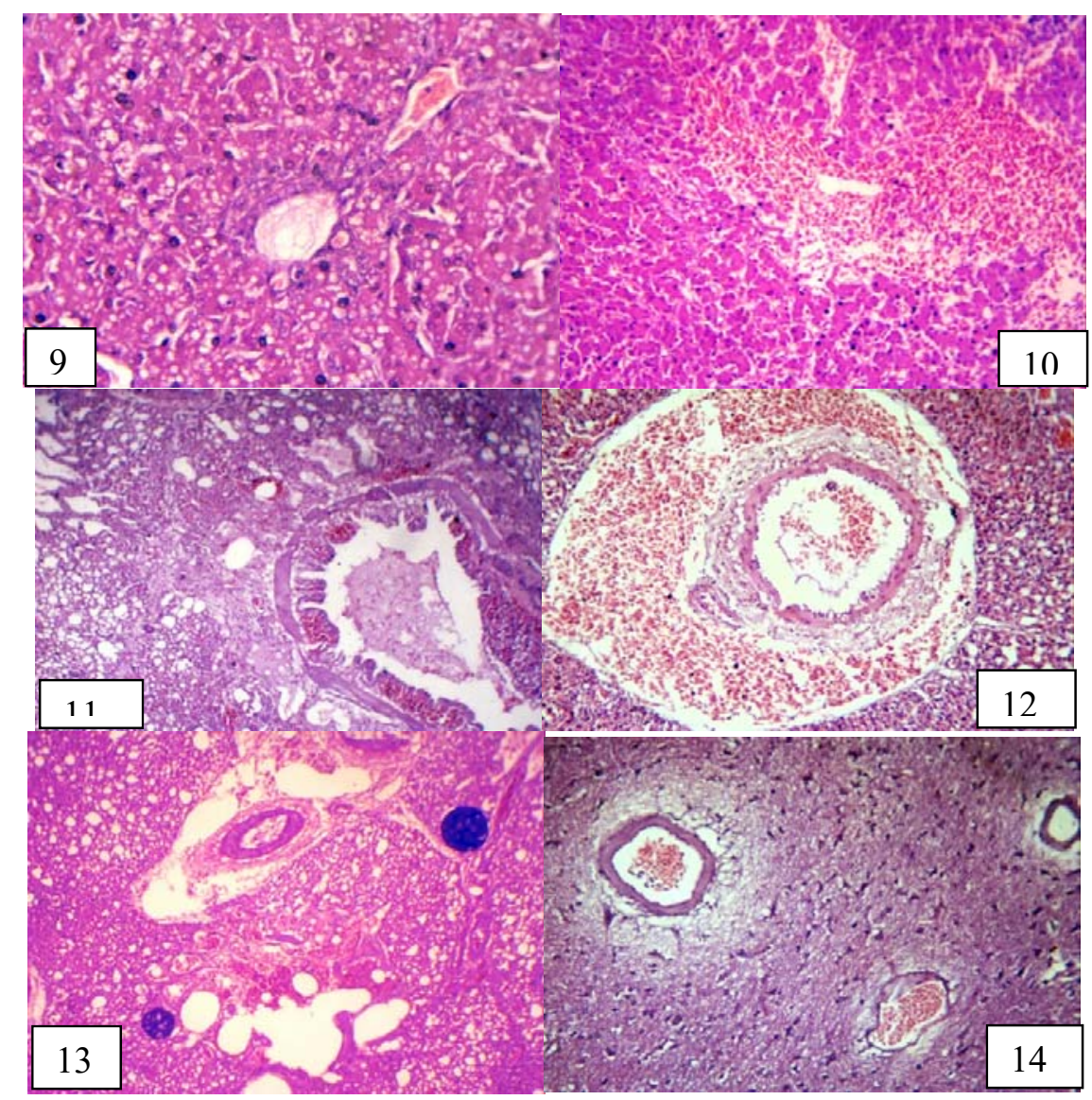

(Fig. 9) Liver of the chicken after 2 weeks from urea administration by concentration of 5\% showing vacuolar degeneration and fatty changes in the hepatocyte. H\&E x200. (Fig. 10) Liver of the chicken after 5 weeks from urea administration by concentration of $5 \%$ showing diffuse area of hemorrhage in hepatic parenchyma. H\&E x100. (Fig. 11) Lungs of chicken after one week from urea administration by concentration of $1.25 \%$ showing mild catarrhal bronchitis represented by bluish mucin in the bronchiolar lumen. H\&E x 200. (Fig. 12) Lungs of chicken after 4 weeks from urea administration by concentration of $1.25 \%$ showing severe perivascular hemorrhage and degenerative changes in the endothelial cell lining pulmonary blood vessels. H\&E x 200. (Fig. 13) Lungs of the chicken after one week from urea administration by concentration of $5 \%$ showing presence of nodules of hyaline cartilage in the pulmonary tissue. H\&E x100. (Fig. 14) Brain of chicken after 2 weeks from urea administration by concentration of $1.25 \%$ showing multifocal severe congestion of the brain blood vessels with perivascular edema. (H\&E x 200). 


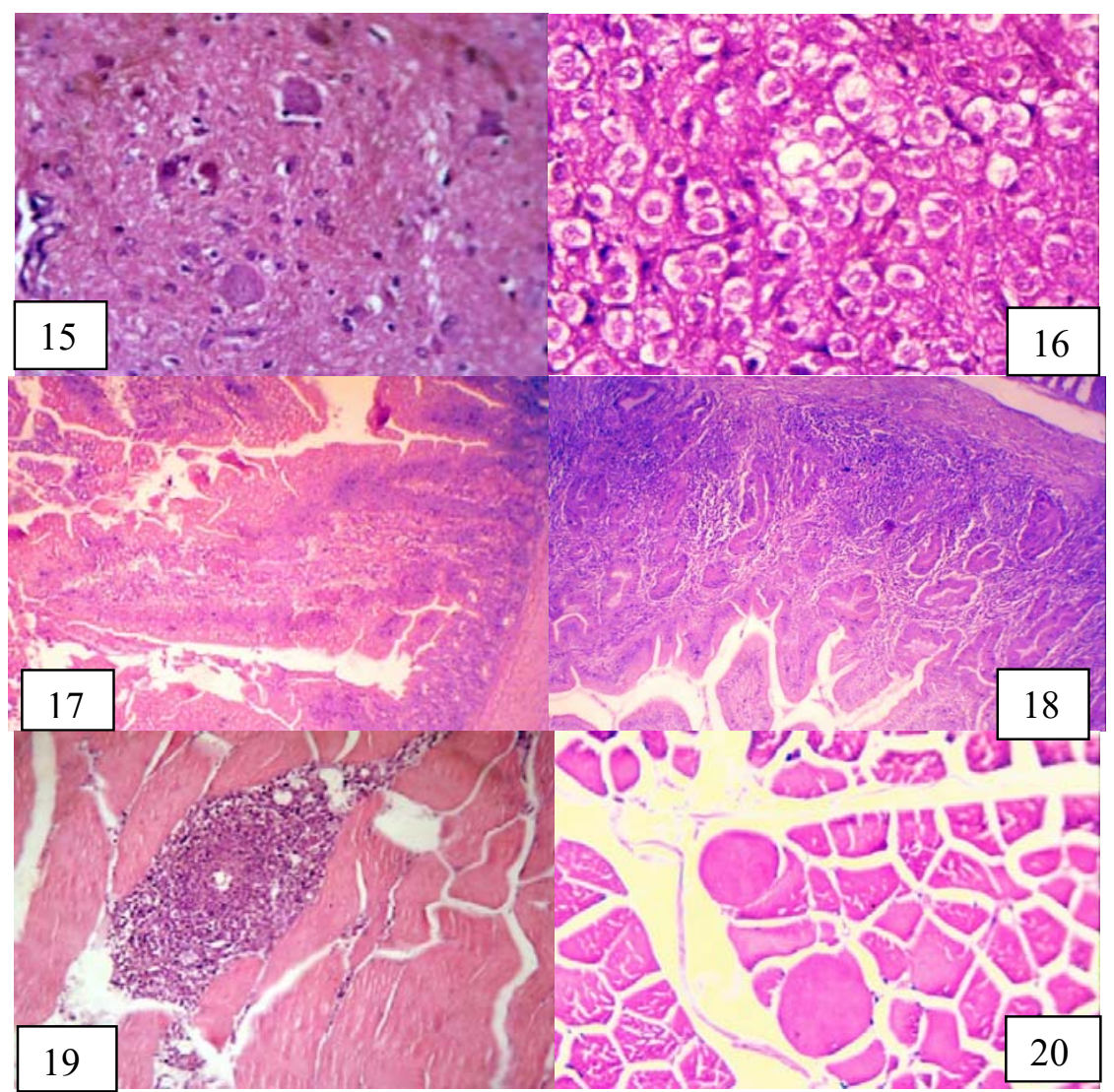

(Fig. 15) Brain of chicken after 5 weeks from urea administration by concentrarion of $2.5 \%$ showing neurophagia and Tygrloysis with satellotosis. (H\&E x400) (Fig. 16) Brain of chicken after one week from urea administration by concentration of 5\% showing demyelination of the axon of the neuronal cell. H\&E x400 (Fig. 17) Intestine of chicken after one week from urea administration by concentration of $2.5 \%$ showing mild desquamation of the epithelial cell lining the villi H\&E x100. (Fig. 18) Intestine of chicken after 5 weeks from urea administration by concentration of 5\% showing heavy leukocytic infiltration in lamina propria of intestinal mucosa. H\&E x 100. (Fig. 19) Muscle of chicken after 5 weeks from urea administration by concentration of $1.25 \%$ showing hyaline degeneration of few muscle fibers with intramuscular leukocytic aggregation. H\&E x 200(Fig. 20) Muscle of chicken after 4 weeks from urea administration by concentration of $2.5 \%$ showing hyaline degeneration of few muscle fibers. H\&E x200.

Table (1): Feed consumption / gm/ chick, Body gain/gm /chick and FCR of experimental broiler chickens :

\begin{tabular}{|c|c|c|c|c|c|}
\hline Parameter & Week & $* \mathrm{I}$ & II & III & IV \\
\hline \multirow{6}{*}{$\begin{array}{l}\text { feed consumption } \\
(\text { (gm) }\end{array}$} & 1 & 210.1 & 210.6 & 205.7 & 204.22 \\
\hline & 2 & 360 & 371.6 & 356.8 & 378.6 \\
\hline & 3 & 1005 & 680 & 509 & 668.63 \\
\hline & 4 & 1300 & 1025 & 910 & 1005 \\
\hline & 5 & 1350 & 1300 & 1200 & 1250 \\
\hline & 6 & 1460 & 1450 & 1400 & 1400 \\
\hline \multirow{6}{*}{$\begin{array}{c}\text { Body gain } \\
\text { (gm/chicks) }\end{array}$} & 1 & 179.4 & 180 & 174.6 & 173 \\
\hline & 2 & 281.6 & 273.8 & 225.4 & 313 \\
\hline & 3 & 520.5 & 434.7 & 360 & 407.52 \\
\hline & 4 & 600 & 570 & 480 & 540 \\
\hline & 5 & 660 & 625 & 509 & 616 \\
\hline & 6 & 700 & 650 & 580 & 652 \\
\hline \multicolumn{2}{|l|}{ Total body weight } & 2881.5 & 2733.5 & 2329 & 2701.5 \\
\hline \multirow[t]{6}{*}{ Feed conversation ratio } & 1 & 1.17 & 1.17 & 1.178 & 1.18 \\
\hline & 2 & 1.27 & 1.357 & 1.582 & 1.20 \\
\hline & 3 & 1.93 & 1.564 & 1.413 & 1.64 \\
\hline & 4 & 2.166 & 1.798 & 1.687 & 1.861 \\
\hline & 5 & 2.045 & 2.08 & 2.357 & 2.029 \\
\hline & 6 & 2.085 & 2.23 & 2.413 & 2.147 \\
\hline
\end{tabular}


Table (2): Results of statistical analysis of urea residue in the muscle and liver of the experimental chicks $(\mathrm{mg} / \mathrm{gm}):-$

\begin{tabular}{cccclc}
\hline \multicolumn{2}{c}{ Groups } & \multicolumn{2}{c}{ Urea level in muscle mg/gm } & \multicolumn{2}{c}{ Urea level in liver $\mathrm{mg} / \mathrm{gm}$} \\
Groups & $\mathrm{N}$ & Mean & $\mathrm{SD}$ & Mean & $\mathrm{SD}$ \\
\hline I & 5 & $1.3656^{\mathrm{b}}$ & 0.74014 & $1.740^{\mathrm{c}}$ & 0.45607 \\
II & 5 & $1.4202^{\mathrm{b}}$ & 0.24097 & $2.920^{\mathrm{b}}$ & 0.77589 \\
III & 5 & $3.0533^{\mathrm{a}}$ & 0.40589 & $7.560^{\mathrm{a}}$ & 0.92898 \\
IV & 5 & $1.0840^{\mathrm{b}}$ & 0.54580 & $0.318^{\mathrm{d}}$ & 0.13274 \\
Total & 20 & 1.6612 & 0.88987 & 3.1345 & 2.84979 \\
\hline
\end{tabular}

(Means values \pm S.D.) With different superscript (a, b, c, d) within the same column are significantly different at $p<0.05$. I: Group fed $1.25 \%$ urea. II: Group fed 2.5\% urea. III: Group fed 5\% urea. IV: Control group.

Table (3): statistical Results of Chemical composition of the muscle of the experimental chicks:

\begin{tabular}{cccccccccc}
\hline \multicolumn{2}{c}{ Groups } & \multicolumn{2}{c}{ moisture \% } & \multicolumn{2}{c}{ CP\% } & \multicolumn{2}{c}{ Ash\% } & \multicolumn{2}{c}{ Lipid\% } \\
& $\mathrm{N}$ & Mean & SD & Mean & SD & Mean & SD & Mean & SD \\
\hline I & 5 & $71.510^{\mathrm{a}} \mathrm{b}$ & 0.85580 & $26.766^{\mathrm{a}}$ & 0.77768 & $1.226^{\mathrm{b}}$ & 0.08295 & $0.444^{\mathrm{b}}$ & 0.08019 \\
II & 5 & $71.031^{\mathrm{b}}$ & 1.03556 & $27.040^{\mathrm{a}}$ & 1.03102 & $1.406^{\mathrm{a}}$ & 0.04930 & $0.476^{\mathrm{b}}$ & 0.09581 \\
III & 5 & $72.306^{\mathrm{a}}$ & 1.18885 & $26.160^{\mathrm{a}}$ & 1.18870 & $1.240^{\mathrm{b}}$ & 0.04123 & $0.288^{\mathrm{b}}$ & 0.04087 \\
IV & 5 & $70.515^{\mathrm{b}}$ & 0.15700 & $26.416^{\mathrm{a}}$ & 0.31825 & $1.276^{\mathrm{b}}$ & 0.10900 & $1.620^{\mathrm{a}}$ & 0.27749 \\
Total & 20 & 71.3412 & 1.06783 & 26.5955 & 0.88766 & 1.2870 & 0.10069 & 0.7070 & 0.56361 \\
\hline
\end{tabular}

(Means values \pm S.D.) With different superscript (a, b, c, d) within the same column are significantly different at $p<0.05$. I: Group fed $1.25 \%$ urea. II: Group fed $2.5 \%$ urea. III: Group fed $5 \%$ urea. IV: Control group.

The brain of group I showed mild degenerative changes in the neuron and severe congestion of the brain blood vessels with perivascular edema. Group II and III showing severe congestion of brain and menengial blood vessels. The endothelial lining of the brain blood vessels showed proliferation. The neuron was suffering from Tygrolysis with presence of satellotosis and neurophagia. Moreover, focal areas of encephalomalacia especially in the brain substance in the granulosa cell layer of cerebellum with leukocytic infiltration.

The intestine showed degenerative changes, desquamation of the epithelial cell lining of the intestinal villi and hyperplasia in the goblet cells of intestinal villi. Heavy leukocytic infiltration in the lamina propria of mononuclear type. Microscopically, the muscle showing mild congestion of intramuscular blood vessels with few erythrocytes in between the muscular bundles. Myomalecia of some muscle cell with mild degree of hyaline degeneration. The muscle of group III showed congestion of the intramuscular blood vessels. Focal mononuclear leukocytic infiltrations were also seen in between the muscle tissue

\section{DISCUSSION}

The present work aimed to investigate the histopathological aspects, growth performance, urea residue in muscle and liver and chemical composition of the breast muscles of birds fed graded levels of urea treated ration. In this study, the most clinical signs were demonstrated in the form of respiratory dyspnea, staggering gait and watery diarrhea. These clinical signs were also described by Abdou 
et al. (2006) and Shahzad et al. (2012). Our results were partially agreed with Chandra et al. (1984) who found weak legs, paralysis in young birds and painful swelling of the hock joints; Unice Satya Latha and Rajyasree (2012) and Frimpong (2013) who found bloody diarrhea, paralysis, and sudden death.

In the present work the results of chick performance in the group birds fed $1.25 \%$ and $2.5 \%$ urea when compared to control showed increase in body weight and feed consumption from the first week of age till the end of the experiment. The FCR was not differ between the urea treated groups and the control. These findings were in agreement with Isikwenu (2008), Unice Satya Latha and Rajyasree (2013). Meanwhile, Landers et al. (2012) and Brand et al. (2012) found that urea treated diets had decreased feed intake and body weight gain leading to bad conversion rate.

In the present work, urea residue in the muscle and liver of the group III showed significant increase when comparing with the other groups. Moreover, urea residue in the liver was higher than in the muscle tissue. These findings were in agreement with Lu et al. (2009), Yan et al. (2009), Sirilaophaisan et al. (2010), Brand (2011) and Landers (2012). However, El-khawaga (1999) found that the cumulative effect of the urea on the skeletal muscle was more than in liver which was calculated by the tissue residue.

In the present work, the chemical composition of the muscle of the experimental chicks showed that the moisture content in the muscle of 5\% urea treated group was high than the control group. There was non-significant increase in the crude protein in birds fed $2.5 \%$ urea. But there was significant increase in ash percent in birds fed $2.5 \%$ urea. The fat content in the muscle of all urea treated groups was significant decrease than the control group. Our results were partially agreed with Rasool et al. (2013) who found that the ash percentage in muscle was significantly higher in birds fed highest levels of urea with copper sulphate and low crude protein percentage. Our results were not agreed with that mentioned by Abdel Raheem (2008) who stated that there was no significant difference in chemical composition of muscle in 5 groups of broiler chickens given diets with $3 \%$ or $10 \%$, or untreated from 1 to 56 days.

Our results revealed that, kidneys macroscopically were slightly enlarged in size and congested but in group II and III showed severe enlargement with pale anemic coloration. Hemorrhagic spots were also detected. The liver was enlarged and congested. In some cases necrotic foci and bronze discoloration were seen. There was severe distention in the gall bladder. Lungs were congested and edematous and dark brownish color. The brain showed hyperemia. The muscles of groups I was slightly congested but in group II petechial and linear hemorrhage found in the breast muscle.

Our microscopic examination of the kidneys showed degenerative changes in the form of vacuolation in the cytoplasm of the epithelial cell lining the renal tubule. Moreover, in group III, the renal tubules showing severe degree of desquamation of the epithelial cell lining with the presence of hyaline cast in their lumen, severe inter tubular and periglomerular hemorrhage, the glomeruli showing shrinkages of their glomerular tuft, thickening and hyalinization of the Bowman's capsules as well as hypercellularity of glomerular tuft and synechia. Similar microscopic findings were previously recorded by Unice Satya Latha and Rajyasree (2013) and Wang et al. (2015). Moreover, our results partially agree with that mentioned by Sanad (1988) and Ahmed (1996) who recorded focal infiltration of polymorphnuclear leucocytic inflammatory cells, swelling of the mesengial cells lining the glomerular tuft and thickening of serosa; Landers et al. (2012) who recorded moderate to severe multifocal accumulation of eosinophilic to basophilic mineralized casts within renal tubules and collecting tubules. Renal lesions may be attributed to the biochemical mechanism by which NPN causes toxicity. Karasawa et al. (1988) stated that when urea was added to a high protein diet a large amount of ammonia could be produced rapidly in the caeca. It might "spill-over" into the blood stream with subsequent development of ammonia toxicity.

Regarding to our microscopical examination of the liver of chicks, focal areas of necrosis in the hepatic parenchyma infiltrated with some of mononuclear leucocyte. Liver in group II and III showed vacuolar and hydropic degeneration or even fatty changes in the cytoplasm of hepatocyte and severe thickening of the hepatic capsule. Massive areas of hemorrhage among the hepatic parenchyma were also seen. The bile duct showed hyperplasia of their epithelial cell lining with the presence of desquamated epithelia in the ductile lumen with newly formed bile ductile and mild portal fibrosis was also detected. The hepatic blood vessels and hepatic sinusoids showed severe congestion and dilatation. Most of hepatic blood vessels showed thrombosis. Our microscopic findings completely agreed with Ahmed (1996) and Gao et al. (2010). 
Regarding to the microscopical examination of the examined lungs, severe congestion of pulmonary blood vessels and capillaries with perivascular edema, hemorrhages and the endothelial cell lining of the pulmonary blood vessels were suffering from degenerative changes. The pulmonary blood vessels showed the presence of thrombosis in their laminae. The bronchioles showed hyperplasia with presence of eosinophilic exudate in their lumen. Lungs showed clear catarrhal bronchopneumonia. There were cartilaginous and osseous nodules among the pulmonary tissue. These microscopic findings completely agreed with Abdou et al. (2006); Elkhawaga (1999) who reported similar lesions in chicks. Moreover, the lung showed emphysema and air alveoli of the lung tissue showed focal epithelization of the lining epithelium with dilatation and desquamation of the epithelial layer.

In the present study, the microscopical findings in the examined brain were congestion of menengial blood vessels. The endothelial lining of the brain blood vessels showed proliferation. The neuron was suffering from Tygrolysis with presence of satellotosis and neurophagia especially in cerebellum with leukocytic infiltration. These finding were in complete accordance to that recorded by El-khawaga (1999), Abdou et al. (2006) who found focal gliosis and perivascular edema.

The histopathological finding of the intestine in the present work revealed the occurrence of degenerative changes, desquamation of the epithelial cell lining of the intestinal villi and heavy mononuclear leukocytic infiltration in the lamina propria. Hyperplasia in the goblet cells of intestinal villi. These microscopic findings were in partial agreed with Ahmed (1996) and El-khawaga (1999) who found hypertrophy of the muscular layer, inflammatory cells mainly eosinophils, lymphocytes and macrophages were infiltrated in the sub epithelial layer of the duodenum. Thick edematous serosal layer and hemorrhage were noticed in lamina propria and sub mucosa in all urea concentration. Our microscopic findings were completly agreed with Abdou et al. (2006), Shahzad et al. (2012) and Frimpong (2013).

In the present work, the histopathological finding of the muscle revealed the occurrence of mild congestion of intramuscular blood vessels with few erythrocytes in between the muscular bundles. Myomalecia of some muscle cell and mild degree of hyaline degeneration. Focal mononuclear leukocytic infiltrations were also seen in between the muscle tissue. These finding in complete agreement with El-khawaga (1999).

\section{REFERENCES}

Abdel-Raheem, H. A., Sayed, A. N., Gazia, N., ElMaswary, S. M. 2008. Evaluation of urea as a protein source in broiler diets. Assiut Vet. Med. J., 119 (54): 1-17.

Abdou, K. A., Mubarak, M. Sharkawy, A. A. 2006. Toxo-pathological effects induced by urea in broiler chicks. Beni-Suef Vet. Med. J., 16 (1): 75-84.

Ahmed, M. A. 1996. Pathological studies on some different organs of poultry due to replacement of urea as a source of protein in ration. M.V.Sc. Thesis, Cairo Uni. Fac. of Vet. Med.

AOAC, (Official Methods of Analysis of the Association of Official Analytic Chemists) 1990. $15^{\text {th }}$ Ed. Edited by Kennesh Helrich, Arling-ton, Virginia, 2220, U.S.A.

AOAC 2000. Official Methods of Analysis (19 ${ }^{\text {th }}$ Ed.) AOAC Inter. Inc. Washington, DC. Pp.1219.

Banchroft, D. J., Cook, C. H., Stirling, R. W., Turner, D. R. 1996. Manual of histopathological techniques and their diagnostic application. $\left(3^{\text {rd }}\right.$.ed.) Chuchill Livingston, Edinburg.

Brand, L. m. 2011. Effects of dietary melamine and cyanuric acid in young broilers and turkey poults. M.V.Sc. Thesis, Fac. of the Graduate School, Uni. of Missouri-Columbia.

Brand, L. M., Murarolli, R. A., Gelven, R. E., Ledoux, D. R, Landers, B. R., Bermudez, A. J, Lin, M., Rottinghaus, G. E. 2012. Effects of melamine in young broiler chicks. Poult. Sci., 91: 2022-2029.

Brown, C., Cathy, A., Jeong, K., Poppenga, R., Puschner, B., Miller, D., Ellis, A., Kang, K., Sum, S., Cistola, A., Brown, S. 2007. Outbreaks of renal failure associated with melamine and cyanuric acid in dogs and cats in 2004 and 2007. J. Vet. Diagn. Investig. 19 (5): 525-531.

Chandra, M., Singh, S., Gupta, P. P., Ahuja, S. P. 1984. Comparative pathogenesis of nephritis in poultry induced by high protein, high calcium, urea and vit. A deficient diet. Acta. Veterinaria, 34: 113-134.

Damron, W. S. 2006. Introduction to Animal Science, Global, Biological, Social and Industry Perspective (third Ed.). U. S. A., Person Educational Inc.

Daszkiewicz, T., Gugolek, A., Janiszewski, P., Kubiak, D., Czoilk, M. 2012. The effect of intensive and extensive production systems on carcass quality in New Zealand white rabbits. 
Wolrd Rabbit sci., 20: 25-32.

Dorne, J.L., Doerge, D.R., Vandenbroeck, M., FinkGremmels, J., Mennes, W., Knutsen, H.K., Benford, D. 2013: Recent advances in the risk assessment of melamine and cyanuric acid in animal feed. Toxicol. Appl. Pharmacol., 270: 218-299.

El- Khawaga, A. E. 1999: Studies of the morphohistopathological alterations in poultry experimentally affected with urea toxicity. Ph.D. Thesis, Dept. Path. Vet. Med. Univ. Cairo, Egypt.

Frimpong, I. O. 2013: Performance of broiler chickens fed water and urea treated neem (Azadirachta Indica) kernel cake as protein supplements. M.V.Sc. Thesis, Department.of Animal Science, Kwame Nkrumah University of Science and Technology, College of Agriculture and Natural Resources.

Gao, C. Q., Wu, S. G., Yue, H. Y., Ji, F., Zhang, H. J., Liu, Q. S., Fan, Z. Y., Liu, F. Z., Qi, G. H. 2010: Toxicity of dietary melamine to laying ducks: biochemical and histopathological changes and residue in eggs. J. Agric. Food Chem., 58: 5199-5205.

Isikwenu, J. O. 2008: Response of weaner rabbits fed graded levels of urea-treated and fermented brewer's dried grains in place of groundnut cake. J. Nat. and Appl. Sci. 2 (11).

Jabbar, L. 1994: Pathology of experimentally induced urea toxicity in broiler chickens. M.V.Sc. Thesis, Dept. Vet. Path., Univ. Agri. Faisalabad, Pakistan.

Karasawa, Y., kawai, H., Hosono, A. 1988: Ammonia production from amino acids and urea in the caecal contents of the chicken. Comparative Biochemistry and Physiology, 90B: 205-207.

Kobayashi, S., Koike, H., Itoh, H. 1981: Effect of dietary urea on nitrogen excretion in cockerels. jpn. poult. sci., 18: 78-85.

Landers, B. R. 2012: Effects of dietary melamine and cyanuric acid in young pekin ducks and weanling pigs. M.V. Sc. A Thesis, Faculty of the Graduate School Univ. of Missouri-Columbia.

Landers, B. R., Murarolli, R. A., Gelven, R. E., Brand, L. M., Ledoux, D. R., Bermudez, A. J., Rottinghaus, G. E. 2012: Effects of Melamine in Young Pekin Ducks. Int. J. Poult. Sci., 11 (12): 730-738.

Liu, J. m., Ren, A., Yang, L., Gao, J., Pei, L., Ye, R., Qu, Q., Zheng, X. 2010: "Urinary tract abnormalities in Chinese rural children who consumed melamine-contaminated dairy products: A population-based screening and follow-up study". Cana. Med. Assoc. J. 182
(5): 439-43.

Lu, M. B., Yan, L., Guo, f. J. Y., Li, f. Y., Li, f. G. P., Ravindran, J. V. 2009: Melamine residues in tissues of broilers fed diets containing graded levels of melamine. Poult. Sci., 88: 2167-2170.

Maynard, L. A., Loosli, J. K., Hintz, H. F., Washes, R. G. 1985: Animal Nutritional (7th Ed.). Tata McGraw-Hill Publishing Company Limited, NewDelhi, India.

Pervaz, S., Javed, M. T., Pervaiz, S. 1993: Studies on feed consumption, feed conversion, live body weight and clinical signs in urea induced toxicity in broiler chicks. Singapore Vet. J., 17: 51-57.

Pervaz, S. 1994: Hematological and enzymological studies of urea induced toxicity in broiler chicks M.V.Sc. (Hons.) thesis, Dept. Vet. Path., Univ. Agri. Faisalabad, Pakistan.

Pervaz, S., Javed, M. T., Sabri, M. A., Pervaiz, S. 1996: Hematological and biochemical findings in broilers feed different levels of urea. Pak. Vet. J. 16: 75-77.

Rasool, A., javed, M. T., Akhtar, M., Bhatti, S. S., Shahzad, M. N., Hussain, R. 2013: Effects of urea and copper sulphate on some serum biochemical and meat parameters in broiler chicken. Pak.Vet. J., 33(1):27-31.

Sanad, A. W. A. F. 1988: Studies on gout in chickens. M.V.Sc. Thesis, Fac. of Vet. Med. Cairo Univ.

Shahzad, M. N., Rasool, A., Javed, M. T., Shabir, S., Irfan, M., Hussain, R. 2012: Effects of feeding urea and copper sulphate in different combinations on live body weight, carcass weight, percent weight to body weight of different organs and histopathological tissue changes in broilers. Exp. Toxicol. Pathol., 64(3): 141-147.

Sharma, K., Paradakar, M. 2010: The melamine adulteration scandal. Food Sec. 2 (1): 97-107.

Sirilaophaisan, S., Khajarern, J., Tengjarernkul, B. 2010: Effects of dietary melamine or ureaformaldehyde or their mixtures on performance, carcass quality, melamine residues and microscopic changes in broiler tissues. Thai. J. Vet. Med., 40 (4): 367-375.

Sucio, J., Miclea, V.,Tat, I., Lozone, D. 1990: Effect of replacing part of the protein in the diet with urea, in the presence of volcanic tuff zeolite, on the performance of Broiler chickens. Bulitinal Institutilui Agronomic clij Napoea. 44: 13-18.

Unice satya latha, V., Rajyasree, M. 2012: Effect of carbamide on serum biochemical aspects of chick. Int. Quarterly Life Sci. J., 7(4): 695696. 
Unice Satya Latha, V., Rajyasree, M. 2013: Effect of carbamide (urea) on histopathological aspects of chick gallus domesticus (Vanaraja Inter). J. of Advanced Res., 10 (1): 103-106.

Wang, L., Ding, X. M., Zhang, K. Y., Bai, S. P., Wu, C. M. 2015: Toxicity of cyanuric acid to broilers on: hepatic and renal health with and without melamine. Human and Exp. Tox., 31(2): 166-173.

WHO. Melamine and cyanuric acid: toxicity, preliminary risk assessment and guidance on levels in food. Sep. 25, 2008. http://www.who.int/foodsafety/fs management/Melamine.pdf.

Yan, L., Guo, J., Sun, Z., Zhu, S., Rong, J., Sui, L., $\mathrm{Lu}$, M. 2009: Melamine residues in tissues of ducks fed diets containing graded levels of melamine. http://en.cnki.com.cn/Article en/CJFDTOTALZGJQ200913007.htm 2011. 